\title{
Implementación de la política social: espacio de intermediación clientelar. Análisis de caso, La Plata, Argentina
}

\author{
Andrea Peroni*
}

\begin{abstract}
Resumen
El presente artículo abordará la implementación de la política social mediante el estudio de cuatro tipos de programas sociales en la localidad de Altos de San Lorenzo de la ciudad de La Plata, Argentina. Se indaga en el tipo de relaciones de intermediación clientelar (Auyero, 2004) que se establecen (o no) según la variación de las condiciones de implementación y los niveles de interacción con los beneficiarios. Dentro de los hallazgos se encuentra una clara práctica de intermediación que fluctúa entre un clientelismo político y una intermediación clientelar-programática, así como la existencia de diferentes tipos de capital social intermediado por distintos actores claves, claramente identificados según las características de los programas sociales analizados. La metodología utilizada fue cualitativa: se realizaron entrevistas semiestructuradas (29) a destinatarios e intermediarios de los ocho programas sociales considerados. La muestra fue de tipo estructural, construida mediante el procedimiento de bola de nieve. Asimismo, se aplicó una encuesta de redes sociales que permitió efectuar un análisis de los vínculos establecidos y el capital social generado.
\end{abstract}

Palabras clave: Política social - clientelismo - intermediación - Argentina.

\begin{abstract}
This article will address the issue of social policy implementation, through the study of four types of social programs in the village of Altos de San Lorenzo, city of La Plata, Argentina. The type of intermediation relationships of patronage (Auyero, 2004) established (or not) is investigated, according to the variation of implementation conditions and levels of interaction with beneficiaries. Among the key findings there are a clear intermediation practice that fluctuates between political patronage and patronage-programmatic intermediation, and the existence of different types of social capital mediated by different stakeholders, clearly identified depending on the characteristics of social programs analyzed. The methodology was qualitative: 29 semi-structured interviews were conducted with recipients and intermediaries of the eight tested social programs. The sample was structural, built by snowball. Also a social networks survey-that allowed the analysis of established linkages and generated social capital- was performed.
\end{abstract}

Keywords: Social policy - clientelism - intermediation - Argentina.

* Departamento de Sociología, Universidad de Chile. Doctora en Estudios Americanos con especialidad en Estudios Sociales y Políticos, Universidad de Santiago de Chile. 


\section{INTRODUCCIÓN}

El estudio acerca de la implementación de la política social da cuenta respecto de cómo las decisiones políticas se desenvuelven en la práctica. La presente investigación se enfoca en dicha fase, visibilizando la interacción que se genera entre los actores, ya que estos "pueden actuar porque poseen cierta información y poder que resultan necesarios para la toma de decisiones" (Maldonado, 2011: 273) y para el allegamiento de bienes y servicios públicos. La interacción que surge de ellos -funcionarios públicos, intermediarios y beneficiariosconforma modelos relacionales que varían en los diferentes tipos de programas sociales. $\mathrm{Si}$ bien la intervención pública está sujeta a un diseño programático establecido en las leyes y normativas, la implementación transita desde el mundo simbólico de quienes toman decisiones (políticos planificadores, productores de conocimiento y legisladores) hacia los aspectos dinámicos más inciertos y resistentes de las realidades sociales cristalizadas en escasez de recursos, relaciones de poder, conflictos de valores, resistencias, retraimiento y pasividad (Brehm y Gates, 1999). Las relaciones de intermediación en la entrega de bienes y servicios públicos no responden necesariamente a la dimensión establecida como normativa, sino a las dinámicas de las relaciones.

La intermediación clientelar suele identificarse con el clientelismo político, entendido este como una "práctica política basada en el intercambio de favores que se da entre clientes (ciudadanos), mediadores (punteros) y patrones políticos (funcionarios)". Así, Auyero comprende al clientelismo como un evento que forma parte de la "resolución rutinaria de problemas de las clases populares, un elemento dentro de una red de relaciones cotidianas" (Auyero, 2004: 29). Estas prácticas se instalan como una modalidad de intercambio habitual, que se produce de manera informal pero permanente por medio de redes establecidas.

A diferencia de la intermediación de tipo clientelar-política (informal, orientada a la acumulación de poder, al apoyo político, a las lealtades y votos, que conlleva la resolución inorgánica de necesidades), en el presente estudio interesa observar la intermediación clientelar-programática que se desarrolla dentro del marco normativo de la implementación, donde la protocolización establece otras reglas del juego para el tránsito de bienes y servicios públicos entre los funcionarios estatales y los beneficiarios e intermediarios de la misma. Se refiere al estudio que se establece "al interior del campo de las políticas sociales [donde] existe un subcampo o microcampo clientelar, en el cual además del clientelismo político se encuentran expresiones de lo que se ha dado en Ilamar [...] como clientelismo social" (Peralta, 2006: 13).

La investigación analiza las dinámicas que despliegan los actores (beneficiarios e intermediarios) en el espacio de la implementación. Los casos en estudio corresponden a los siguientes programas sociales de Argentina: Asignación Universal por Hijo; Plan Más Vida; Programa Jóvenes por Más y Mejor Trabajo; Mamá y Bebé Sanos; Cooperativas de Trabajo; Presupuesto Participativo; Comedores; y Emergencia Habitacional. Los programas sociales y sus actores se analizaron in situ en la delegación municipal de Altos de San Lorenzo, Provincia de Buenos Aires, Argentina. 


\section{LA IMPLEMENTACIÓN DE LAS POLÍTICAS SOCIALES Y EL CLIENTELISMO}

\subsection{Política social, implementación y programas sociales en Argentina}

\subsubsection{Política social en Argentina}

Los procesos de cambio económico y político de comienzos del nuevo milenio han venido a alterar la forma de la estructura social de Argentina, demarcando las orientaciones estratégicas de la política social en la actualidad. La crisis del año 2001 ilustra un cambio en la estructura social que hasta ese entonces se había mantenido estable frente a otras transformaciones económicas. Las nuevas masas empobrecidas se sumaron a la población pobre de carácter más estructural -con un aumento del desempleo (que subió de 6,3\% en 1992 a 18,3\% en el 2001)-, dando paso a un país con altos índices de desigualdad. El nivel de ingresos reales de las familias descendió en 7,1\% en 1996; luego 13\% en 1998; y ya en el 2001 alcanzó 30\% (UNICEF y CEPAL, 2006). Gran parte de la población estaba sumida en la pobreza y la vulnerabilidad. Ello marca una distancia enorme con la Argentina de hace cuatro décadas, que contaba con un alto nivel de ingresos, bajos índices de desigualdad y la red de protección social más avanzada de América Latina.

Las garantías de seguridad económica que forman parte del sistema de protección social argentino se vinculan al tipo de inserción laboral que tienen (o tenían) los beneficiarios. Los seguros, asignaciones, transferencias o prestaciones eran percibidos por aquellos ciudadanos que tenían un empleo formal. La crisis del 2001 y 2002 marcó un punto de inflexión en las tendencias de la política social, al focalizarse en extrabajadores con empleo formal, en los desocupados. Lo anterior ha implicado que durante la última década se haya consolidado una política social focalizada en la gestión de riesgos y vulnerabilidades de las familias, a partir de programas contributivos y no contributivos (Bertranou et al., 2011).

El Gráfico 1 muestra la evolución del gasto social en Argentina respecto del Producto Interno Bruto (PIB). Es posible observar que, si bien después de la crisis el gasto público social disminuyó, a partir del 2005 se ha logrado recuperar y expandir.

\subsubsection{Distintos tipos de programas sociales - distintas modalidades de implementación}

La política social se operacionaliza mediante planes, programas y proyectos sociales, dando cuenta de la variedad de modalidades con los que se expresan las orientaciones gubernamentales y se responde a las necesidades de la población.

Considerando que el objeto de análisis es la implementación de la política social, y que la unidad operativa más frecuente es el programa social, a continuación se presentan las distintas características que asumen los mismos. Roberto Martínez Nogueira plantea que la implementación de la política social posee dos dimensiones: por un lado una dimensión simbólica, de quienes toman las decisiones, planificadores y productores de conocimiento; y por otro lado una dimensión social, donde se vislumbran las realidades sociales, las 


\section{GRÁFICO 1}

Porcentaje del gasto social respecto del PIB en Argentina

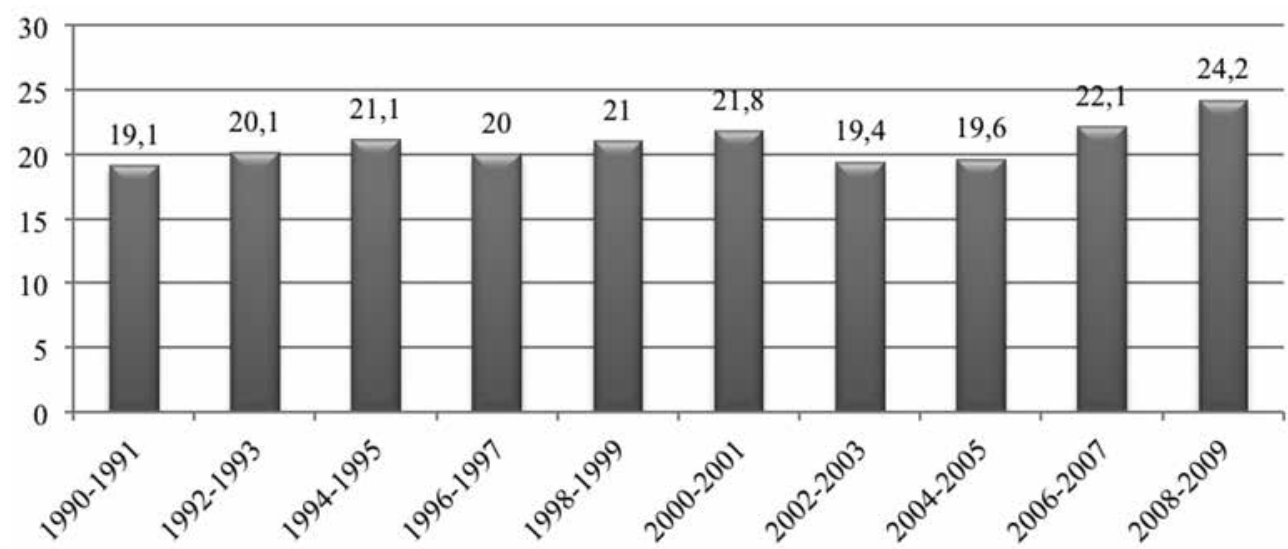

Fuente: Elaboración propia en base a CEPAL (2011).

necesidades que impulsan la generación de las políticas, así como también los conflictos, resistencias y valores de los actores sociales. La primera dimensión se refiere a la naturaleza de las tareas de la implementación, mientras que la segunda hace alusión a la interacción con los usuarios en el desarrollo de la esta. Ambas dimensiones están directamente interrelacionadas; "cuanto mayor es la amplitud de los comportamientos individuales, grupales o comunitarios a impactar, de las actitudes a modificar, de los valores a establecer o de las condiciones de vida a transformar, mayor es la interacción necesaria entre la población objetivo y los operadores. De igual manera, cuanto mayor es la interacción requerida para el suministro del servicio o la entrega de la prestación, mayor es la necesidad de generar mecanismos para la participación de la población, con adaptaciones en las metodologías de programación, seguimiento y evaluación" (Martínez Nogueira, 2004: 82). Según esto, de la naturaleza de la tarea se desprenden dos situaciones, la homogeneidad y la heterogeneidad, mientras que en la interacción con los usuarios es posible encontrar una interacción nula o baja y una interacción media o alta.

Tomando en consideración las dimensiones de la implementación con sus variaciones, Martínez Nogueira (2004) presenta la siguiente tipología de clasificación de los programas sociales:

En primer lugar, la transferencia de bienes y recursos se refiere a aquellas prestaciones de baja complejidad en cuanto a su diseño e implementación. Son programas dirigidos a individuos o comunidades en que se entrega un bien tangible (dinero, alimentos, agua potable) que no implica una alta participación o involucramiento de los beneficiarios, sino que opera desde la oferta. La eficiencia de estos programas suele ser alta y dentro de las desviaciones que es posible encontrar están las ambigüedades en los focos de distribución y prácticas clientelares, entre otras. 
TABLA 1

Tipología de programas sociales según las condiciones de implementación

\begin{tabular}{|l|l|l|}
\hline & \multicolumn{1}{|c|}{$\begin{array}{c}\text { ALTA HOMOGENEIDAD } \\
\text { DE LA TAREA }\end{array}$} & $\begin{array}{c}\text { BAJA HOMOGENEIDAD } \\
\text { DE LA TAREA }\end{array}$ \\
\hline $\begin{array}{l}\text { Interacción nula } \\
\text { o baja }\end{array}$ & 1. Transferencia de bienes y servicios & $\begin{array}{l}\text { 4. Prestaciones asistenciales y de } \\
\text { emergencia }\end{array}$ \\
\hline $\begin{array}{l}\text { Interacción media } \\
\text { o alta }\end{array}$ & 2. Servicios sociales profesionales & $\begin{array}{l}\text { 3. Servicios humanos de desarrollo de } \\
\text { capacidades y de inserción social }\end{array}$ \\
\hline
\end{tabular}

Fuente: Basado en Martínez Nogueira (2004).

Cuando existe homogeneidad en las tareas de implementación y a la vez una interacción media o alta con los beneficiarios, se encuentran los servicios sociales profesionales. Estos programas se caracterizan por "limitarse a atender necesidades o problemas ordinarios, predecibles, con tratamientos e intervenciones respaldados por conocimientos codificados, prácticas, acuerdos y consensos profesionales, rutinas organizacionales o manuales de operaciones" (Martínez Nogueira, 2007: 86). Ejemplos de este segundo tipo son las atenciones en salud y educación en sus distintos niveles.

El tercer tipo de programa se refiere a los servicios humanos de desarrollo de capacidades y de inserción social, los que en la arena de la implementación se caracterizan por una interacción media o alta con los usuarios y por una heterogeneidad en las tareas de gestión. El objetivo de este tipo de programas es transformar al receptor de estos en cuanto a su desarrollo personal, social o en materias de gestión comunitaria. La participación de los beneficiarios en esta tarea es fundamental.

Finalmente, un cuarto tipo de programas son las prestaciones asistenciales y de emergencia. Estas prestaciones poseen heterogeneidad en la tarea en tanto no se rigen por un diseño ni metas claras en su implementación, sino que se desarrollan en situaciones de crisis política, económica y desastres naturales, así como en emergencias individuales que presente la población. "Generalmente estos programas se manejan con escasa precisión respecto de sus beneficiarios, no tienen criterios de focalización definidos, y hay una alta discrecionalidad política en su gestión para controlar la propensión al clientelismo y la arbitrariedad" (Martínez Nogueira, 2007: 94).

De esta manera, y tomando en consideración lo expuesto anteriormente, las dos grandes dimensiones de los programas son: la naturaleza de la tarea y la interacción con los usuarios. Los programas seleccionados son los siguientes (según su ubicación en la tipología):

Por consiguiente, el problema de estudio se configura en el proceso de ensamblaje, donde múltiples actores independientes entre sí poseen recursos básicos para el logro del producto final: el allegamiento de bienes y servicios públicos. Estos actores establecen distintos juegos de negociación/transacción que finalmente se van a transformar en juegos 
TABLA 2

Programas sociales analizados en Altos de San Lorenzo (Argentina), según tipología de Martínez Nogueira (2004)

\begin{tabular}{|l|l|l|}
\hline & HOMOGENEIDAD DE LA TAREA & HETEROGENEIDAD DE LA TAREA \\
\hline Interacción nula o baja & $\begin{array}{l}\text { - Asignación Universal por Hijo. } \\
- \text { Plan Más Vida. }\end{array}$ & $\begin{array}{l}\text { - Comedores. } \\
- \text { Emergencia Habitacional. }\end{array}$ \\
\hline Interacción media o alta & $\begin{array}{l}\text { Programa Jóvenes por Más y } \\
\text { Mejor Trabajo. } \\
\text { - Programa MaBeS (Mamá y Bebé } \\
\text { Sanos). }\end{array}$ & - Presupuesto Participativo. \\
\hline
\end{tabular}

Fuente: Elaboración propia.

de confianza, viabilizando la implementación de los programas sociales (Bardach \& Eccles, 1991). En especial, en estos juegos se observará cómo se despliega la intermediación clientelar enmarcada en reglas programáticas. La observación se realiza en cada uno de los programas sociales antes mencionados, y el análisis se concluye por cada tipo de programa social (Transferencias; Servicios; Desarrollo de Capacidades; Emergencia).

\subsection{Acerca de los clientelismos}

\subsubsection{Clientelismo político}

El clientelismo, entendido como la relación de dominación entre el patrón y el cliente, ha sido abordado en contextos democráticos tanto en Argentina como en Chile, vinculado a la generación de efectos negativos para la transparencia y participación, y a prácticas tradicionales de los partidos políticos. Esta práctica se ha adaptado a distintos contextos sociales y ha tomado nuevas formas que indican su perdurabilidad, ligada a la participación política (e incluso con legitimidad cotidiana).

En Argentina han estudiado el tema Torres P. ( 2002); Auyero (2001,2002, 2004, 2007, 2013); Vommaro y Quiros (2011); Soprano (2008); Zaremberg (2004); y Bustelo (1998), entre otros. Autores como Auyero (2001), Soprano (2008) y Zaremberg (2004) se sumergieron en el clientelismo y las representaciones sociales que se desprenden de estas formas de relación, a partir de trabajos etnográficos en barrios marginales con militantes sociales peronistas. Para Bustelo (1998) la relación caudillo-patrón evoca una dimensión relacionada con el ámbito familiar: la responsabilidad implícita de proteger a los súbditos a cambio de la lealtad a quien ejerce la autoridad. Está también asociada con el carácter no sujeto a reglas con que se ejerce la autoridad. Al caudillo se le tolera la trasgresión y la relación se establece sin mediaciones de una legalidad basada en derechos y obligaciones. La protección y los 
favores son actitudes "graciosas del patrón". La no tributación de lealtad es asimilada a la traición y quien la práctica es excluido de la relación. Por eso los beneficios de los súbditos dependen de la fidelidad.

En Chile lo han estudiado Durston (2004); Valenzuela A. (1977); Barozet (2006); Mardones Z. (2008); Rehren, (2000); y Zambrano, Bustamante y García (2009), entre otros. En relación con la presente investigación, cabe destacar la tipología que desarrolla Durston (2002) a partir de su trabajo de campo en La Araucanía en Chile, donde describe los tipos de interacción entre el capital social y los organismos públicos en la zona de interfaz. Esta tipología corresponde a un continuo que va desde: clientelismo autoritario, represivo y/o cleptocrático; clientelismo pasivo; semiclientelismo; organismos "empoderadores" y apoyadores que profundizan el semiclientelismo; y sinergia, que se caracteriza por comunidades que gestionan sus propias estrategias.

Una modalidad de aproximarse a los distintos matices del clientelismo político es mediante la revisión de la literatura según distintas miradas disciplinarias (Auyero, Joseph y Mahler, 2007). Desde una mirada política, Szwarcberg (2010) plantea que el clientelismo, en vez de desaparecer, se ha consolidado en democracia, en especial en Argentina en el nivel local. El estudio a nivel provincial realizado por Matus (2007) señala las tramas clientelares que cristalizan relaciones de fuerza y sentido, que aparecen completamente naturalizadas en las visiones de quienes viven al día. En ese sentido, el barrio, el territorio, suponen una forma de inscripción social -suerte de reafiliación reactiva a la crisis de las identidades tradicionales-. Se advierte cómo el Estado aparece como co-constitutivo del mundo social, contenido en las tramas relacionales y espaciales del barrio; y lo hace encarnado en la figura de los agentes comunitarios (de diferente tipo) que intermedian la transacción. Desde una perspectiva más antropológica, Auyero (2002) explora una de las dimensiones menos conocidas del clientelismo político: los puntos de vista de quienes reciben favores, los "clientes". Su trabajo hace hincapié en un aspecto particular del intercambio clientelar: la distribución de bienes a cambio de asistencia a actos públicos del Partido Justicialista de Buenos Aires. Especial atención se pone en la doble vida del clientelismo (el intercambio objetivo y la experiencia de los actores) y en la negación colectiva del intercambio en la que participan dirigentes políticos y clientes $^{2}$.

En la misma línea que Auyero, Merklen (2006) indaga en las relaciones protagonizadas por los pobres, definidos como rehenes, sometidos a las redes del clientelismo. Presenta la tensión entre las dos identidades: pobres y ciudadanos, con todas las fuerzas que esos dos términos tienen. Demuestra que la pobreza, incluso en casos muy duros, no disuelve la conciencia de ciudadano.

Desde la perspectiva antropológica, el clientelismo es un universo de relaciones sociales, en cuyo contexto se construyen identidades. El clientelismo político es entendido, por lo

2 Su aporte se centra en las visiones - diferentes- que los "clientes" tienen de la "política clientelar", qué piensan y sienten respecto de estos intercambios, cómo evalúan las actividades de los referentes (punteros políticos) y desde allí la política en general. 
general, como un intercambio de "favores por votos"; pero es, sobre todo, un intercambio relacional que pretende establecer y alimentar una relación personal duradera entre las partes (Merklen, 2005; Durston, 2005). Este tipo de intercambio, mediante redes de relaciones personales, puede ser caracterizado como "capital social individual" que es propiedad del individuo (ego) en el centro de una red con forma de telaraña (Durston, 2002: 350). Quien complementa esta perspectiva desde sus estudios etnográficos es Álvarez Rivadulla (2012), develando la relación que se establece entre el clientelismo y las redes políticas con grupos de ocupantes ilegales en un barrio de Montevideo.

Por su parte, será Barozet (2006) quien enfatizará que el clientelismo se ha adaptado a los nuevos regímenes políticos y es cuestionado porque afecta a la democracia. La autora señala cinco temas fundamentales a la hora de entender el fenómeno en la actualidad, los que permiten orientar el análisis del presente estudio: i) el papel del Estado respecto de la estructura en torno a la que se articula el clientelismo; ii) el tipo de intermediación política existente (respecto al rol de los intermediarios y su participación en la estructura de poder); iii) el esquema de intermediación política, es decir, las redes existentes a nivel local; iv) la diferencia entre la política social y la política clientelar (ya que el clientelismo no necesariamente va dirigido a los sectores más vulnerables); y v) el grado de institucionalización de los intermediarios y su vinculación con los partidos políticos. Los cinco temas viabilizan el análisis del clientelismo tanto político como programático, en tanto lo ubican en su relación con las políticas sociales y con las redes por donde circulan los bienes y servicios públicos.

\subsubsection{Clientelismo programático}

El clientelismo es relevante en cuanto da cuenta de una modalidad de intermediación por donde bajan los recursos a la población. Los "clientes" esperan conseguir en la intermediación distintos tipos de bienes, recursos o servicios públicos ${ }^{3}$. Sin embargo, es importante no entender toda intermediación como clientelar, ni toda práctica de clientelismo político como intermediación de la política social.

Por ello es necesario distinguir las distintas modalidades de distribución de bienes y servicios públicos, a saber: i) distribución programática: refiere a la entrega de bienes y servicios indicados en los protocolos de los planes, programas y proyectos sociales, de acuerdo con el programa de gobierno preestablecido, sin intervención clientelar; ii) distribución

3 i) Dinero, bajo algunas formas de subsidio, retribución y/o crédito accesible para este sector social, pero en todos los casos existe una intervención estatal que se concreta en los diversos programas sociales de aporte económico, con o sin contraprestación; ii) Bienes, ya sean alimentos, útiles escolares, materiales de construcción, remedios, juguetes; iii) Trabajo, empleo formal (que concentra la mayor expectativa y deseo) o informal, más o menos duraderos, incluyendo las "changas" puntuales; iv) Servicios directos, básicamente de salud (realización de radiografías, análisis, ecografías, sesiones de fisioterapias, de manera ágil y resolutiva) y también de tipo administrativo (datos, catastros, etc.); y v) Servicios indirectos, definidos empíricamente como aquellos que posibilitan el acceso a otros bienes o servicios. Están centrados en la gestión o realización de "trámites" necesarios en tanto requisitos exigidos para el acceso a algunos de los bienes mencionados (Peralta, 2006: 79-80). 
clientelar-programática: refiere a la entrega de bienes y servicios programáticos mediante la intermediación de un agente que se mueve dentro de la estructura del programa, y goza de un espacio discrecional de decisión. La intermediación clientelar se efectúa dentro de las reglas del juego del programa social; y iii) distribución clientelar-política-partidista: refiere a la entrega de bienes y servicios públicos mediante la cooptación de votantes que probablemente responderán con apoyo político. El intermediario se mueve fuera de un marco programático específico.

La distribución programática hace referencia a cumplir promesas de campaña por parte de los partidos -apelando a grupos colectivos, con un perfil programático definido, y abstractos, en tanto carecen de individualización preliminar-, como puede ser el aumento de una pensión. La distribución de bienes públicos de tipo clientelar hace referencia a la cooptación de votantes que probablemente responderán con apoyo político al otorgamiento de determinados beneficios (Alonso G., 2007). A este tipo de intermediación se la denominará clientelar-política.

Así, mientras que la distribución programática interpela a categorías sociales como los jubilados, los desempleados, etc., la distribución clientelar busca la cooptación de aquellos votantes que probablemente responderán con apoyo político al otorgamiento personalizado de favores o bienes. De esta manera, lo que hay detrás de una distribución clientelar (política) es una relación de intercambio entre individuos en el contexto -no entre grupos sociales categorizados-.

Los intercambios clientelares (política) en los marcos de la implementación vinculan a un patrón y a un cliente, articulados por una mediación política personalizada en democracia y establecen un circuito de reciprocidad probable entre favores y apoyo político (votos, asistencias a actos, etc.) (Alonso G., 2011: 104-105). Además de fundarse en asimetrías de poder y en la desigualdad de recursos, las relaciones clientelares son particularistas porque no se establecen con bases universales de derechos, sino en vínculos personales e informales, ya que ninguna instancia investida de poder formal aparece como garante del cumplimiento de los arreglos entre los participantes de las redes (Auyero 2001; Torres, 2002, en Idiart, 2011: 15-16).

Acerca de las distinciones antes mencionadas, y a efectos del estudio, se analiza el tipo de intermediación según la distribución de los bienes y servicios públicos, sea i) distribución clientelar-programática (se incluye como categoría específica, en tanto se ha observado un tránsito de acciones de intermediación pero en el marco de los programas) y iii) distribución clientelar-política-partidista.

Finalmente, se concuerda con la definición de Alonso, basada en la reelaboración de la conceptualización y funciones, donde el clientelismo constituye una modalidad de gestión sui generis que permite subsanar por defecto los déficits de capacidades técnicas del Estado para gestionar programas sociales en contextos de escasez de recursos o, en todo caso, "una solución de compromiso", para gestionar las brechas de capacidades hasta que las mismas se potencien (Alonso G., 2011). 


\section{METODOLOGÍA}

Considerando el clientelismo como una relación que se puede establecer en distintos espacios sociales (Tosoni, 2010) -en este caso el espacio de implementación-, las categorías analíticas que se aplicaron en el análisis refieren a (Barozet, 2006):

1. Grado de personalización o individuación del vínculo, en donde temas como el afecto y el compromiso por parte de los clientes puede hacer más eficiente el desarrollo del clientelismo.

2. Grado de legitimidad de los modos de vinculación con lo político. Esta categoría tiene que ver con el grado de aceptación del clientelismo por parte de la comunidad. Mientras más se legitime como forma de intermediación, mayor eficiencia tomará la práctica clientelar y aquellos políticos involucrados tendrían una mayor legitimidad en la comunidad.

3. Grado de obligatoriedad de la retribución, lo que se relaciona con el grado de dependencia de la relación y la afectividad que provoca esta.

No serán analizadas en función de grados debido a que la modalidad de producir la información fue cualitativa, por lo que la mayor presencia o ausencia de estas características del clientelismo serán observadas como énfasis distintos y no grados diferenciados de manera cuantitativa. Asimismo, se considerará la categoría hegemonía de las redes sociales, las que serán observadas a partir de la encuesta de redes aplicada a los beneficios.

En relación con el proceso metodológico, se define de la siguiente manera (Figura 1):

- El estudio es exploratorio y descriptivo, en tanto el abordaje de la intermediación clientelar inserto en marcos programáticos no ha sido suficientemente estudiado como tal.

- La unidad de análisis se estructura basada en la tipología de programas sociales. La primera muestra se establece en la selección de los ocho programas sociales, cubriendo dos programas por tipo, según la naturaleza de la tarea y la interacción con los usuarios.

- La metodología utilizada fue cualitativa -con el fin de conocer el relato y las valorizaciones de los actores-, y se realizó mediante entrevistas semiestructuradas (29). Los ejes de la entrevista refirieron a las modalidades de acceso a los bienes y servicios públicos. La muestra de los actores fue de tipo estructural, construida mediante bola de nieve. La distribución de la muestra abarcó dos funcionarios, dos beneficiarios y uno o dos intermediarios por programa, según las características de los mismos. El procesamiento y análisis de la información cualitativa se realizó mediante uso del software Nvivo, mediante el análisis de contenido.

- Asimismo, se realizó una encuesta de redes sociales ${ }^{4}$, ya que mediante dicha metodología se materializa el intercambio en recorridos observables. Así se pudo "mapear" el tejido

4 Aguirre (2012: 14) señala: "entiendo por red clientelar a un conjunto de actores vinculados a través de una relación clientelar que conforman una estructura de relaciones que los dota de posiciones y roles funcionalmente 
FIGURA 1

Modelo de análisis

- Observación de la

intermediación por medio de:

- Personalización o individuación del vínculo

- Legitimidad de la intermediación clientelar

- Obligatoriedad de la retribución

- Redes sociales (lazos y capital social)

Modelo de análisis

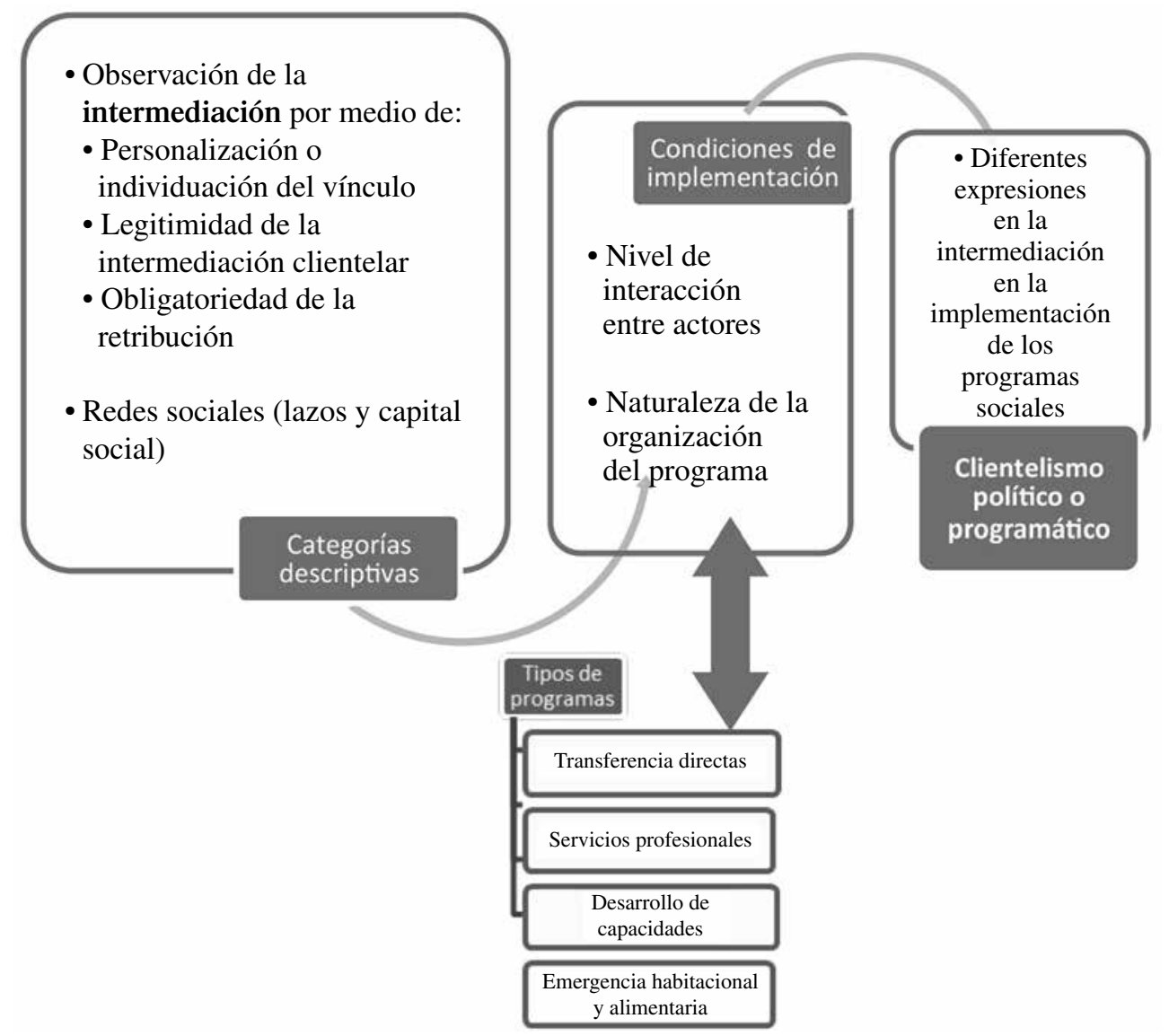

Fuente: Elaboración propia.

social que se conforma según el tipo de programa. Dicha red permitió identificar los capitales que disponen los participantes. Para ello se posicionó a los actores identificados por color y forma en las gráficas, a saber: beneficiarios (rojo); intermediarios (verde); funcionarios (azul); y otros agentes ( $r$ gris) -el cambio de figura geométrica responde a si los mismos son entrevistados (cuadrado) o nombrados (círculo)-. La información base correspondió a la aplicación de la encuesta a los beneficiarios e intermediarios. El análisis de los datos se realizó mediante el uso de UCINET, otorgando los valores correspondientes a los estadísticos propios del $\mathrm{ARS}^{5}$.

diferenciables -patrones, mediadores y clientes- y configura pautas de interacción que condicionan sus acciones y preferencias dentro de ella".

5 En Anexo se presentan las simbologías que permiten la adecuada lectura de las gráficas de redes. 
- Finalmente se complementó con observación participante en los comedores, y monitoreo barrial del programa Mamá y Bebé Sanos (MaBeS). El trabajo de campo se realizó entre marzo y junio del 2011.

\section{HALLAZGOS}

A continuación se presentarán los hallazgos que permiten identificar las características que asume la intermediación clientelar-programática en cada tipo de programa social: transferencias, servicios profesionales, desarrollo de capacidades y emergencias, según sus condiciones de implementación.

\subsection{Transferencia de bienes y recursos ${ }^{6}$}

\subsubsection{Invisibilización del clientelismo-político}

Los grupos que se benefician de las transferencias otorgadas por el Estado podrían estar propensos a prácticas clientelares, como condicionamiento para recibir un determinado bien tangible, resolviendo una necesidad básica. Sin embargo, el clientelismo político en esta categoría de programas se encuentra invisibilizado, es decir, se habla de las prácticas clientelares de manera genérica, pero se omite el término en relación con este tipo de programas. Lo anterior se puede deber a las connotaciones negativas que posee el concepto o al no involucramiento de los entrevistados en dichas prácticas, si aparece la relación clientelar-programática.

La explicación de lo anterior se encuentra en las condiciones de operación de los programas. Por un lado, la implementación de la Asignación Universal por Hijo (AUH) se realiza de manera homogénea desde el servicio público a cargo de la Administración Nacional de la Seguridad Social (ANSES), mediante chequeo de las condiciones mínimas según base de datos de alcance nacional; ello sin duda elimina la posibilidad de intermediar la entrega del subsidio. La entrega de la AUH es directa y con mínimo contacto con el beneficiario, primando una racionalidad técnica-gestora (sin intermediación) en tanto apropiación directa del beneficio.

En el caso del Plan Más Vida (PMV), la intermediación está presente y es definida institucionalmente mediante la figura de la manzanera y la comadre. $Y$ desde dicha modalidad de implementación es posible encontrar elementos de discrecionalidad que dan cuenta de las prácticas clientelares-programáticas, como por ejemplo la información que manejan y transmiten.

6 Los programas analizados fueron el Plan Más Vida y la Asignación Universal por Hijo. El Plan Más Vida es de carácter provincial y se orienta a mejorar las condiciones nutricionales de madres y niños en situación de vulnerabilidad socioeconómica en la Provincia de Buenos Aires; mientras que la Asignación Universal por Hijo es un subsidio entregado por el Ministerio del Trabajo, que consiste en un monto fijo de dinero que se entrega a las familias por cada hijo menor. 
Si bien no se observa en el relato una práctica clientelar-política propiamente tal en ambos programas (AUH y PMV), sí existe una variación en la apreciación de las beneficiarias del PMV por el tránsito de bienes al que pueden acceder. La acción de la manzanera y de la comadre reemplazaría la labor de la institucionalidad pública en la administración de los recursos. Y si bien ellas no son las responsables del stock disponible, sí se puede apreciar un espacio de arbitrariedad (o desorden) en la provisión de los mismos desde el estado provincial.

“Me había enterado que acá no había [ropa para recién nacidos]. Es un tema que depende cómo se manejan, es de una manera que, viste... Por ahí se organizan [...], y no entra nada, como te digo han dado ropa ajuar para chicos ya nacidos. Yo tengo una amiga que se anotó y tenía mellizos y le dieron por uno no más por un embarazo y eran gemelas. Puede ser por el cambio político porque están pasando estas cosas" (Gisela, Beneficiaria $\mathrm{AUH}$, referido a la entrega de ajuar del PMV).

La personalización o individuación del vínculo (entre cliente y patrón) no se observa en este grupo, pudiendo atribuirse al ocultamiento de la práctica o porque simplemente no se generan afectos o compromisos en los beneficiarios, con el poder político y los intermediadores partidarios. El vínculo más estrecho se establece con la manzanera, por medio de la entrega de la leche (día por medio), siendo ese el espacio de autonomía de la intermediaria para otorgar más o menos unidades. E incluso ella puede incluir transitoriamente o excluir a sus beneficiarias, hasta que la institucionalidad indique su estado definitivo. Claramente se establece una relación de intermediación clientelar-programática. Distinta es la relación que se establece entre la comadre y la beneficiaria, ya que es de corta duración, relativa al embarazo y puerperio.

Respecto de la legitimidad del clientelismo-programático, es posible visualizar en las entrevistadas un interés de participar de la relación. Este interés sería en función de la obtención del beneficio directo (entrega de mercadería, ajuares, etc.) y no por generar un compromiso político con la proveedora de los recursos. La obligatoriedad de la retribución es nula en ambos programas. En la AUH, por el anonimato en la gestión del mismo. En el PMV, si bien existe un espacio de discrecionalidad en la entrega de la leche o en la inclusión en el programa de parte de la manzanera, ello no refiere a un vínculo que implique una retribución política partidaria, sino en favores más bien cercanos a la vida cotidiana, por ejemplo apoyar en la entrega de las meriendas en el comedor del barrio.

El tránsito de favores, bienes, servicios se puede observar en un tejido social donde los beneficiarios, intermediarios y funcionarios son actores relevantes. En el caso de los programas de transferencia de bienes y recursos, adquiere la siguiente forma ${ }^{7}$ (Gráfico 2):

7 Se sugiere volver al apartado de Metodología para realizar la adecuada lectura de los gráficos de redes, así como observar en Anexo la simbología utilizada. 


\section{GRÁFICO 2}

Redes en los programas de transferencia de bienes y recursos

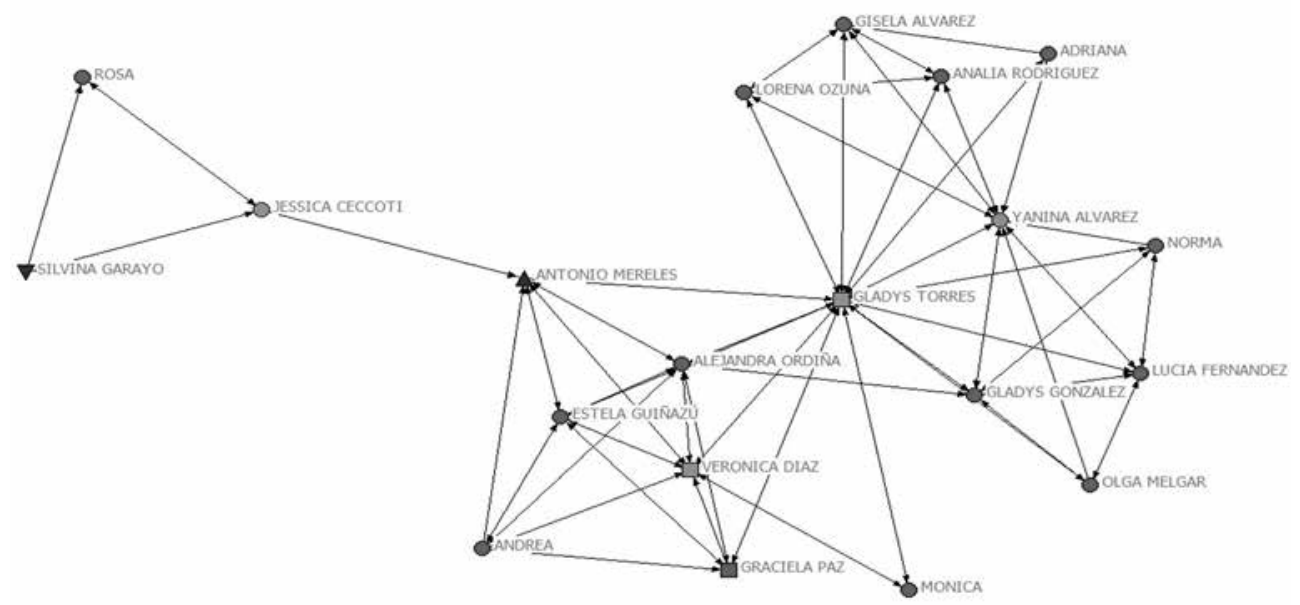

Fuente: Elaboración propia.

Se puede apreciar una red poco jerarquizada, donde las relaciones centro-periferia se ubican solamente en un centro en torno a la intermediaria Gladys Torres, quien hace más de 10 años que se desempeña como manzanera del PMV, siendo su casa el centro de distribución de leche fresca (pasteurizada -no en polvo-). A su vez ella conecta por lazos manifiestos (densos, de confianza y cooperación) y por lazos preexistentes al resto de la red. Hacia la periferia de la red se encuentran contactos vinculados solamente con una persona. Ello significa una baja repitencia en los nombres de interlocutores, "lo cual indica que la red pertenece a un campo que no está cerrado sobre sí mismo" (Espinoza, 2006: 5). Y a su vez refiere a un notable nivel de aislamiento de dichos beneficiarios, en relación con los lazos comunitarios o incluso estatales.

La red se expande hacia la periferia mediante la acción del delegado municipal, Antonio Mereles, quien aparece estrechamente conectando a aquellas personas que poseen menos capital social. No obstante, las relaciones que se conforman con él son más bien preexistentes, no manifiestas de manera directa al realizarse la encuesta, lo que es posible de relacionar con la "invisibilidad" del clientelismo político en los beneficiarios de transferencias y servicios. La figura del delegado municipal es importante en tanto él constituye un "lazo débil" porque conecta una red con otra, aunque no sería estrictamente débil en términos de Granovetter (2000: 41-56, en Villasante, 2006), ya que sí ostenta un puesto de poder. Y su sola mención da cuenta de prácticas de intermediación política-partidaria, aunque no reconocidas como tales.

El núcleo central de la red visualiza lazos que refieren a los grados de confianza vincular, porque poseen un "capital social" exclusivo, un capital social de unión ${ }^{8}$ más que de

8 Redes familiares, de amistad cercana y de vecindad/comunidad. Involucra nexos con personas significativas; y en términos geográficos tiende a implicar nexos con personas que viven muy cerca. 
puente ${ }^{9}$ y prácticamente nada de escalera ${ }^{10}$. Por esta razón, refleja la desvinculación de los beneficiarios de este tipo de programas sociales con intermediaciones políticas clientelarespartidarias (salvo la presencia del delegado municipal).

\subsection{Servicios profesionales ${ }^{11}$}

\subsubsection{Valorización estratégica del clientelismo político}

En el segundo tipo de programas sociales es posible encontrar -a diferencia de lo anteriorun relato explícito acerca del clientelismo político por parte de las entrevistadas. Si bien por un lado hay una aceptación de esta forma de intermediación (existiendo mayor legitimidad de la práctica clientelar), también existe una crítica hacia los políticos y el gobierno por no hacerse cargo de las necesidades que posee la población. Es en este contexto donde se encuentra un doble juego, por un lado la aceptación del beneficio como una estrategia de parte de los beneficiarios para suplir sus necesidades, por otro lado no hay elementos que los pudiesen relacionar con la dominación (votos por chapas). La estrategia en este caso es clara: recibir y luego dar (chapas por votos), lo que pone a los políticos en una situación diferente a la que tenían antaño. Una de las características del clientelismo en este tipo de programas sería entonces las exigencias del cliente, quien condiciona su apoyo político a la retribución otorgada:

“Pero, qué pasa, la gente ahora, recién ahora se está avivando. Porque la gente era muy, como muy criatura, ¿me entendés? La gente le decía, 'no, mirá me va a dar esto, sí voy a votarlo', pero después cuando llegaban las elecciones, cuando ganaban las elecciones, a la gente que le hacían promesas, nunca llegaban... Entonces la gente ahora se está avivando, vos primero dame las cosas que me vas a dar, yo te voy a votar" (Romina, Beneficiaria MaBeS).

El grado de personalización o individuación del vínculo por parte de los beneficiarios asume características particulares. Si bien se apoya a un candidato, esto se hace en función del beneficio. Se encuentra en este caso un alto apoyo y participación, pero que sin embargo está limitado a la obtención del recurso. La alta participación en la relación de intermediación que se presenta hace más eficiente al clientelismo político, porque el involucramiento y compromiso es mayor. No obstante, la negación de la acción política sigue presente, lo

9 Redes organizacionales: juntas vecinales, comunidades de campesinos, madres solteras y otras formas federativas de organización.

10 Redes entre grupos y personas de distinta identidad y distintos grados de poder sociopolítico. Nexos que crean relaciones medianamente consolidadas entre personas/comunidades y agencias públicas o no gubernamentales externas. Facilitan el acceso a esferas políticas, a recursos de agencias externas, al apoyo de estas agencias en momentos de crisis o amenaza, u otros (Arriagada, Miranda, y Pavez, 2004: 20).

11 Los programas analizados fueron el Programa Jóvenes por Más y Mejor Trabajo y el Programa Mamá y Bebé Sanos. El Programa Jóvenes es de carácter nacional y se orienta a generar oportunidades de inclusión social a través de facilitar y fomentar el acceso a capacitación y empleo de calidad. Por su parte, el programa Mamá y Bebé Sanos es de carácter municipal y del área de salud municipal, focalizado en embarazadas, puérperas y lactantes. El programa integra las prestaciones nacional, provincial y municipal de salud y nutrición para este grupo objetivo, distribuye la oferta entre el grupo objetivo y monitorea el efectivo acceso a esta. 
que refleja que a pesar de la práctica propiamente tal y del reconocimiento de esta, sigue persistiendo una connotación negativa hacia el clientelismo-político-partidario:

"yo no soy ninguna política ni nada, pero yo hablo con ellos, viste '¿quieren tener beneficio?, colabora $[\ldots]^{\prime}$ yo si les tengo que cubrir el día lo voy a hacer cubrir, hablo como una política más, no lo soy, pero si les tengo que cubrir el día a un compañero para que nos acompañe a un acto" (Daiana, Beneficiaria Programa Jóvenes por Más y Mejor Trabajo)

Otro aspecto a destacar es a quiénes buscan los políticos para llevar a cabo prácticas clientelares: ¿buscan a los más necesitados?, ¿qué sucede una vez que llegan al poder? En este sentido el discurso es claro: "los políticos se olvidan de la gente", lo que demuestra que las prácticas clientelares no son permanentes y, una vez conseguidos los votos, es posible dejar de llevarlas a cabo, al estar "arriba" en el escalafón de la política. Lo efímero de esta práctica puede dar cuenta de que en algunos casos no se logre generar mayor identidad política o compromiso político en los beneficiarios, y que su mayor o menor participación dependa de los beneficios que puedan recibir. La legitimidad del vínculo está erosionada (y desprestigiada) por el uso político-instrumental del mismo:

“Ellos, los políticos, ven al alcance de sus ojos, porque hay gente que en verdad no lo necesita, porque no lo necesita, y ellos se lo dan, y le dan. $Y$ hay gente que en verdad lo necesita, y no le dan nada. Y yo he visto gente que está descalza, chicos descalzos, con los mocos chorriando... y vos decís y ¿dónde está la gente que tiene que estar acá con estos chicos? Nadie ve eso, nadie ve eso, te da tristeza, te da impotencia... te dan ganas de agarrar, y hacer reaccionar y traer acá a los políticos, hacerles reaccionar: mirá, tu pueblo te dio esto, y tú te olvidaste de tu pueblo. Porque verdaderamente los políticos se olvidan de la gente, que es cuando suben arriba" (Romina, Beneficiaria MaBeS).

Se desprende una mirada estratégica y antipolítica acerca de la intermediación clientelarpolítica, donde se reconoce la obligatoriedad de la retribución desde el cliente al intermediario, pero también desde el intermediario al cliente, ello significa que la personalización del vínculo se enmarca en el derecho a la retribución, más que a la constitución identitaria, afectiva (como puede ser en los programas del tipo I con la manzanera).

Finalmente es importante mencionar que en el programa MaBeS existe la figura de la monitora de salud, persona de la comunidad que realiza la acción de pesquisa y monitoreo de las embarazadas y puérperas. Trabaja en el terreno y se coordina con la obstetra y enfermera del centro de salud local. Su figura corresponde a una intermediación clientelar-programática, ya que su conocimiento del sector salud y su experiencia como dirigente social le permiten transferir información a las beneficiaras más allá de su función como monitora (visitante). Su rol y posicionamiento se puede apreciar en la red de Gráfico 3 (Esther G.).

A continuación se presenta la red de relaciones que se tejen los beneficiarios e intermediarios de los programas de servicios profesionales (Gráfico 3).

Se puede apreciar una red más jerarquizada, donde las relaciones centro-periferia se ubican solamente en un centro en torno a la figura del delegado municipal (Antonio), quien tiene militancia política y es reconocido en el sector pues hace más de cuatro años que se 


\section{GRÁFICO 3}

Redes en los programas de servicios profesionales

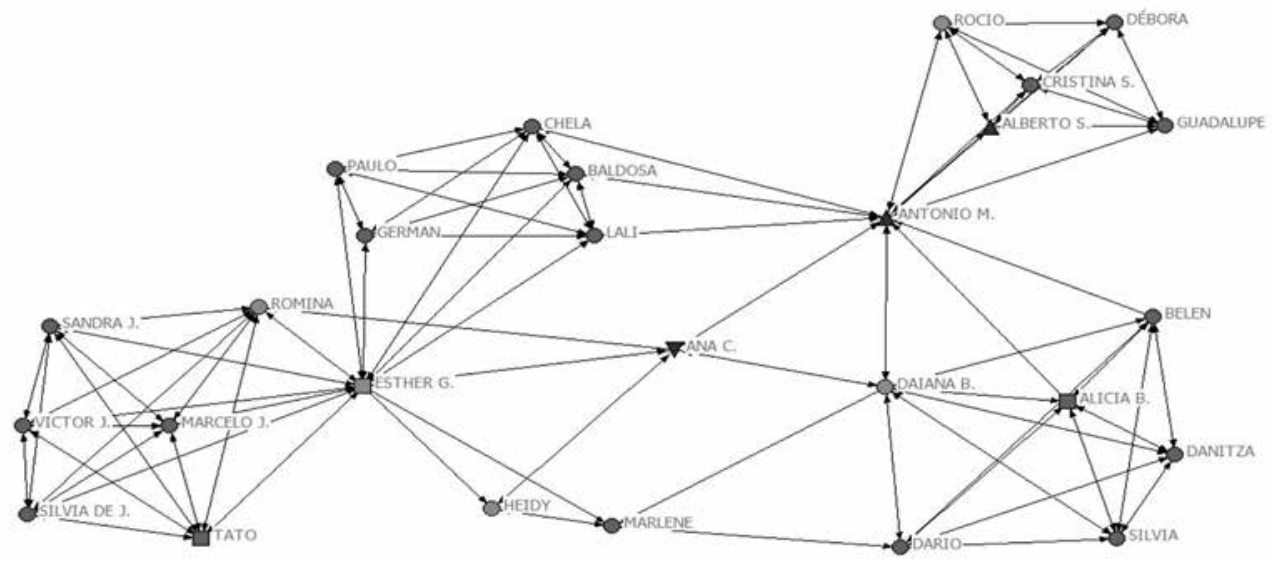

Fuente: Elaboración propia.

desempeña como delegado (antes tenía un negocio de alimentos en el barrio). A su vez, él conecta por lazos manifiestos (densos lazos de confianza y cooperación) y por lazos preexistentes al resto de la red. El otro nodo que contrapone la centralidad que ejerce Mereles está constituido por el rol que ocupa Esther, reconocida intermediaria del sector, quien en relación con este tipo de programas cumple el rol de monitora en terreno del Programa MaBeS. Esta red presenta una densidad considerable en tanto existe una alta repitencia en los nombres de interlocutores, esto indica que la red pertenece a un campo más cerrado sobre sí mismo, en cada conjunto de nodos.

\subsection{Desarrollo de capacidades e inserción social ${ }^{12}$}

\subsubsection{Legitimación y estrategia: ¿de qué clientelismo nos beneficiamos?}

En este tipo de programas el conocimiento de las estrategias clientelares-políticas es claramente reconocida por los entrevistados y es posible a partir de eso encontrar dos visiones.

12 Los programas de desarrollo de capacidades e inserción social analizados fueron: Argentina Trabaja, Cooperativas de Trabajo de La Plata y el Presupuesto Participativo. Argentina Trabaja es un programa orientado a generar empleo mediante la organización en cooperativas de trabajo que funcionan como proveedoras de servicios públicos, en donde los beneficiarios tienen acceso a tres tipos de prestaciones: empleo, ingreso y capacitación. Las Cooperativas de Trabajo son programas orientados a generar empleo mediante la organización de los trabajadores desocupados en cooperativas, las que proveen de mano de obra tanto al municipio como al sector privado. El Presupuesto Participativo es un programa que permite a la comunidad involucrarse activamente en la formulación de proyectos de desarrollo local específicos, tanto de infraestructura como de acción social, y la asignación presupuestaria para su financiamiento se establece a partir de mecanismos de participación directa implementados desde el municipio. 
Por un lado, la que ejerce, legitima y "naturaliza" las prácticas, y por otro lado quien conoce las prácticas pero no tiene la necesidad de llevarlas a cabo porque al conocer la estrategia no necesita del clientelismo político para conseguir el beneficio. Desde dichos caminos se presenta entonces una racionalidad política y una racionalidad gestora en relación con las prácticas clientelares, en el desarrollo de capacidades.

En el primer caso, quienes legitiman las prácticas conocen cómo se realiza el proceso "desde arriba", es decir, cómo baja el beneficio para que llegue a la población en búsqueda de votantes y apoyo político. En ese sentido aparece la figura del puntero político, quien para el caso argentino cumple el rol de referente político. Y este referente, en relación con el programa Presupuesto Participativo, es la figura del intermediador clientelar-político-partidario.

“En cada candidatura política a ellos le dan determinada plata para que hagan su publicidad y esas cosas. Entonces, desde ahí, de eso tan sencillo, que ponen carteles por todos lados, en épocas electorales... eh publicitándose... lo hacen con sus punteros y los recursos ellos se lo reparten a los punteros políticos. Entonces después los punteros hacen lo que ellos [los políticos] le piden, convencen a la gente para que vote un proyecto participativo, o sea el proyecto que los políticos quieren... y otras cosas, y les bajan a la gente" (Beneficiario, Presupuesto Participativo).

Se reconoce un grado de obligatoriedad de la retribución. En la medida en que se participe de las movilizaciones serán entregados los recursos. La responsabilidad recae directamente al beneficiario, ya que debe asegurar su compromiso en la dinámica.

"Y el que no vaya, no va, no está, bueno podés faltar tres, cuatro, cinco veces, pues ya si no vas te dan de baja" (Sergio, Beneficiario Cooperativa La Plata).

La última característica respecto del clientelismo político de los programas que desarrollan capacidades es el carácter estratégico que asume la práctica desde el beneficiario.

"Depende del candidato lo que le va ofreciendo, y con quien se alía. Entonces, eso depende del mejor postor, digamos. Y muchos van cambiando constantemente" (Sebastián, Beneficiario Presupuesto Participativo).

La posibilidad de rotación que tienen los beneficiarios de estos programas entre los candidatos depende del ofrecimiento que se realice, lo que abre la competencia entre los políticos por generar acumulación de poder, captar participación política, haciendo de la práctica clientelar una dinámica cada vez más atractiva para los clientes, aumentando sus ganancias a cambio de apoyo político con la posibilidad de cambiarse en la medida en que aparezcan nuevos y mejores oferentes. En el caso de los Presupuestos Participativos compiten las propuestas de proyectos a ser votadas por los vecinos y luego obtener el apoyo de la municipalidad para ser ejecutadas. Y en el caso de las Cooperativas refiere a las ofertas de cupos o aperturas de Cooperativas con financiamiento estatal. La legitimidad que asume el clientelismo en este caso es alta, basada en la valoración de proyectos o cupos a conseguir.

Una segunda visión respecto de la intermediación se aleja de la relación clientelar-política, ya que no necesita de ese juego para conseguir un beneficio. Adapta la estrategia para 
conseguir el beneficio sin necesidad de pasar por el político. Se constituye en intermediador de carácter horizontal y basa su influencia en su capacidad y reconocimiento de sus pares. Se constituye como autointermediador-programático. Esto se dio en el caso del presupuesto participativo en Altos de San Lorenzo, en La Plata, ya que luego de postular por cinco años al beneficio y de ser rechazado todas las ocasiones, el entrevistado decide impulsar la estrategia de captación de apoyo entre sus mismos vecinos.

“Entonces eso fue, yo fui a cada vecino, le digo 'bueno, cada uno de ustedes tiene que juntarme diez (10) personas, si juntamos diez (10) personas somos cuarenta (40) casitas que estamos pidiendo gas, somos cuatrocientas (400), si logramos que cuatrocientas (400) personas vayan a votar, ganamos el presupuesto participativo', y sacamos doscientos cuarenta y dos (242) votos más noventa (90) Ilamados de mensaje de texto, duplicamos al delegado municipal" (Alberto, Intermediario, Presupuesto Participativo).

Esta figura de autointermediador-programático juega "limpio" entre los vecinos y se ofrece su proyecto como un beneficio comunitario, en este caso el gas para la villa. Esta jugada, si bien demoró años en poder ser realizable, demuestra que el conocimiento y empoderamiento por parte de los beneficiarios puede retozar en contra al clientelismo político, ya que se puede acceder al beneficio sin la necesidad de pasar por la cooptación política. La figura del autointermediador-programático no se asume como clientelismoprogramático porque, si bien juega dentro de las reglas del programa, no despliega acciones de acopio de poder discriminatorias o con favoritismos individuales. Otra distinción de esta figura con el intermediador clientelar-político (por ejemplo, el delegado municipal) refiere a cómo visualizan el acopio de poder en relación con la resolución de necesidades. Para el autointermediador, su motivación era resolver una necesidad comunitaria, y por ello propone un proyecto de conexión de gas subterráneo a los hogares del sector. Para el intermediadorpolítico ese proyecto no era "visible", por consiguiente no era redituable políticamente. Dos lógicas encontradas, a pesar de los intentos de Alberto por convencer a Antonio Mereles.

"La proyección política se encuentra en identificar lo que más necesita la gente, te digo 'discúlpame, yo te estoy trayendo un proyecto, es para el futuro', es una proyección política pero infernal, porque si vos ponés el gas, la proyección política que vos podés llegar a tener en el barrio es infernal" (Alberto, Intermediario, Presupuesto Participativo).

En resumen, la presencia de la intermediación clientelar-política en los programas de desarrollo de capacidades es más evidente. La legitimidad de la práctica clientelar aparece mucho más que en los tipos de programas anteriores. En un primer caso, reconoce la personalización o individuación del vínculo, en donde temas como el afecto y el compromiso por parte de los clientes pueden hacer más eficiente el desarrollo del clientelismo y la obligatoriedad de la retribución, siendo una expresión de la racionalidad política. Por su parte, la personalización del vínculo se da de manera más independiente en los beneficios, esto ya que conocen mejor la estrategia y pueden aprovecharse de ella.

Pero también aflora en este tipo de programas la figura de intermediación horizontal, propia de la necesidad de canalizar la resolución de problemáticas comunitarias que se desenvuelve en el marco programático. Este tipo de intermediación se desvincula de manera 
consciente de la personalización o individualización del vínculo, y de la obligatoriedad de la retribución, presentándose por medio de un tipo de racionalidad gestora. Estas dos miradas establecen el reconocimiento de la intermediación, pero a su vez por el objetivo de estos programas sociales se establece una condición de empoderamiento que permite reconocer y elegir moverse dentro o no de las prácticas clientelares-políticas. De esta manera, la red de actores se presenta así:

\section{GRÁFICO 4}

Redes en los programas de desarrollo de capacidades e inserción social

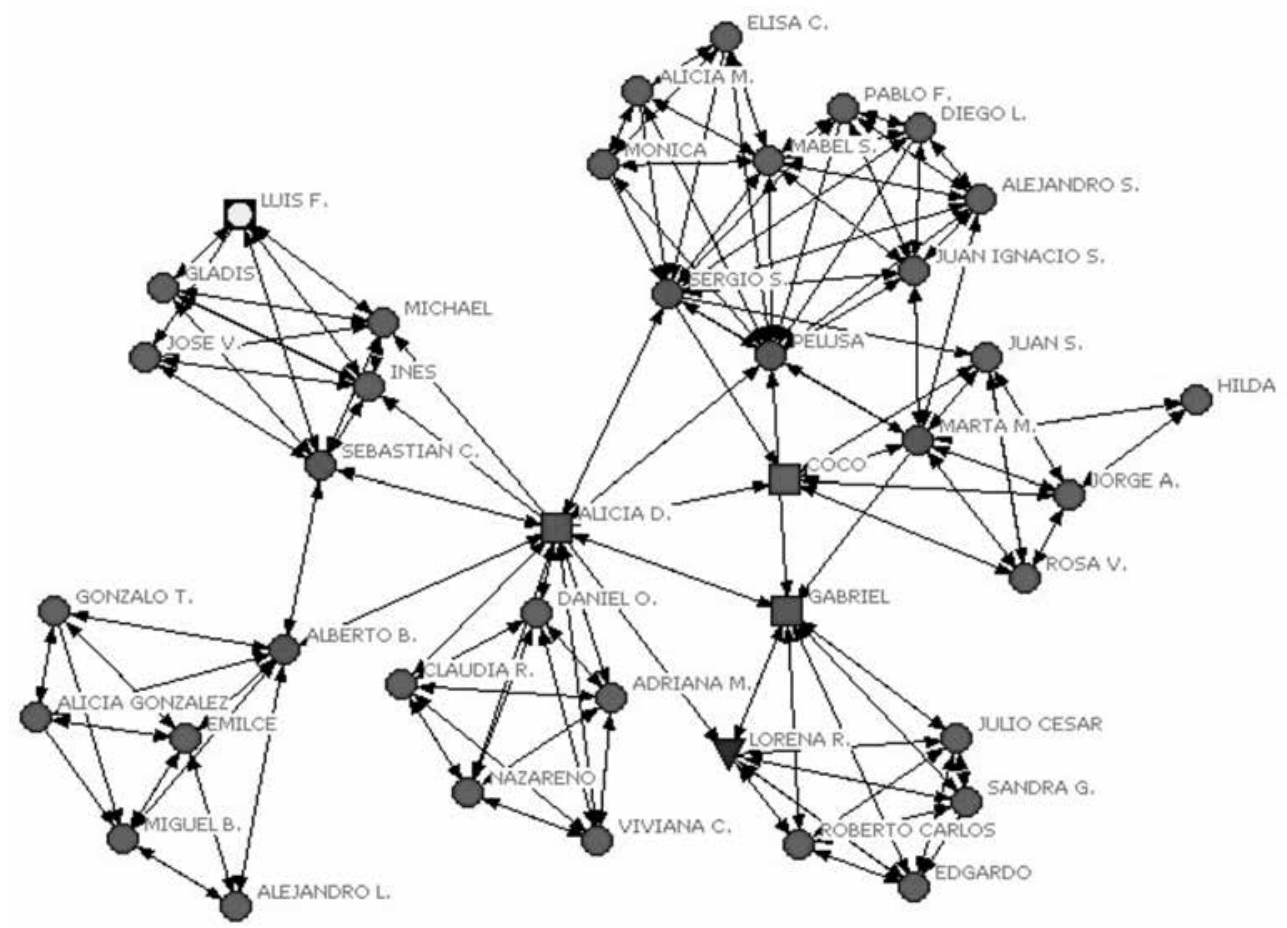

Fuente: Elaboración propia.

Se puede apreciar una red no jerarquizada, donde las relaciones centro-periferia se diluyen y cada nodo asume su propios vínculos. Se observa una red fusionada por lazos preexistentes (refiere a los lazos no declarados como parte del círculo de conversación acerca de política social, pero preexistentes en las relaciones), pero en la que aparecen muchos más astros, siendo estos los mismos beneficiarios y en dos casos intermediarios (Gabriel y Alicia), quienes efectivamente articulan a las comunidades donde pertenecen. Lo anterior demuestra una mayor autonomía por parte de los entrevistados a la hora de hablar de políticas sociales y conseguir beneficios. No hay una hegemonía clara en esta red porque hay muchos puntos que la conectan, $y$ los beneficiarios cumplen el rol de intermediar entre 
sus redes individuales. Los grandes ausentes en este caso se encuentran en las relaciones manifiestas de los beneficiarios y la figura del delegado municipal, quien es partícipe de las otras tres redes, lo que indica una horizontalidad mayor en relación con el poder local.

El núcleo central de la red visualiza lazos que refieren a los grados de confianza vincular, poseen un tipo de capital social circunscrito, manifiesto en capital social de unión, de puente y poco de escalera (ya que hay solo una inclusión de un funcionario público de mayor rango, la concejala Lorena Riesgo). Por esta razón, refleja la vinculación de los beneficiarios de este tipo de programas sociales con intermediaciones políticas clientelares equivalentes a intermediaciones gestoras clientelares, y sin duda con un nivel mayor de empoderamiento de sus miembros.

\subsection{Prestaciones de emergencia ${ }^{13}$}

\subsubsection{El dilema entre participar o no en prácticas clientelares}

Por las características que toman las ayudas sociales del último tipo de programas, se podría pensar que hay una mayor tendencia hacia la intermediación y de tipo clientelarpolítico. La entrega puntual de un bien o servicio podría conllevar la necesidad de generar lazos más estables con los referentes o punteros políticos, para así asegurar la pronta solución a problemas básicos, vinculados a alimentación y vivienda. Además, como las ayudas de emergencia se otorgan en casos específicos, hay menos conocimiento de parte de los beneficiarios de cómo se implementa un programa social y, por tanto, la necesidad de buscar un apoyo extra a la política social se puede volver casi indispensable. El grado de personalización del vínculo -al igual que la transferencia de recursos y bienes- no aparece en este tipo de programas, sin embargo la legitimidad de los modos de vinculación con lo político se manifiesta en tanto se puede acceder al beneficio. De esta forma, la obligatoriedad de la retribución, de parte del "cliente", es parte de la urgencia que conlleva el trato.

"Hay que ir a movilización, que si no vas, ellos te sacan, es todo por interés. Entonces
como yo tenía a mis nenes, y a veces me tenía que ir a una movilización a las doce del
mediodía (12:00), allá en Buenos Aires, hasta la noche, yo no podía dejar a mis hijos todo,
de las doce del mediodía (12:00) o a la mañana hasta la noche" (Yanina, Beneficiaria,
Emergencia Habitacional)

La perspectiva que manifiestan los beneficiarios es estratégica, en tanto la búsqueda de la solución inmediata requiere contactos eficaces y también un vínculo (afectivo de confianza) que permita recurrir de manera presta. No se desconoce la intermediación clientelar-política, no se pelea contra ella, como en el tercer tipo de programas. Los beneficiarios están en una

13 Los programas analizados para el caso de emergencia fueron el programa de comedores barriales y el de vivienda ante precariedad o catástrofes. Ambos no son programas propiamente tales, sino que son ayudas sociales que se activan en situaciones puntuales, algunos casi permanentes y otras ocasionales. 
posición de vulnerabilidad extrema. La personalización del vínculo es la tabla de salvación para resolver la emergencia.

A continuación se presenta la red de relaciones que se establece en los programas de emergencia:

\section{GRÁFICO 5}

Redes en los programas de emergencia

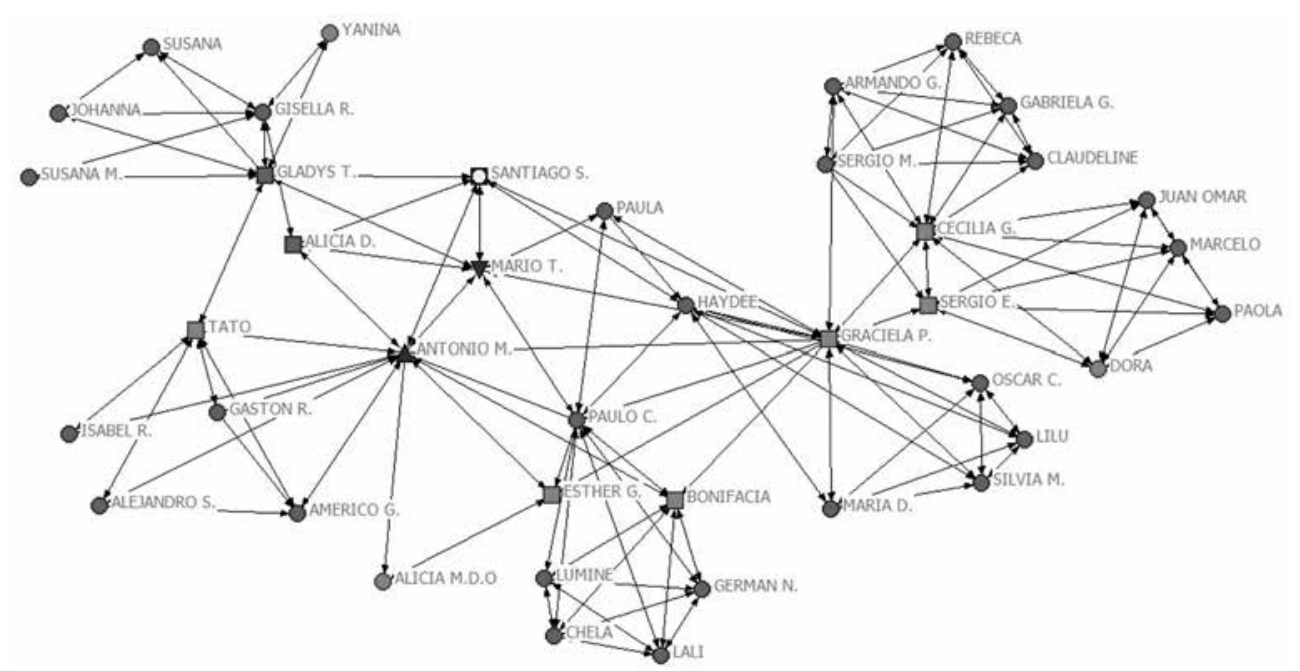

Fuente: Elaboración propia.

Se puede apreciar una red poco jerarquizada, similar al primer tipo de programas, donde las relaciones centro-periferia se ubican solamente en un centro en torno a la figura de Antonio Mereles, el delegado municipal. La figura del delegado municipal vuelve a aparecer con fuerza y ocupa un lugar central en la intermediación política de los bienes y servicios hacia la población, pero no aislado. A su vez, él conecta por lazos manifiestos (densos lazos de confianza, acuerdo y cooperación) y por lazos preexistentes al resto de la red. Hacia la periferia de la red se encuentran contactos vinculados solamente con una persona. Ello significa una baja repitencia en los nombres de los interlocutores, "lo cual indica que la red pertenece a un campo que no está cerrado sobre sí mismo" (Espinoza, 2006: 5).

La red se expande hacia la periferia mediante la acción de diferentes intermediarios (Sergio, Bonifacia, Tato y Graciela), quienes aparecen conectando a aquellas personas que poseen menos capital social. Las relaciones que se conforman son manifiestas, de manera directa, al realizarse la encuesta, lo que es posible de relacionar con la visibilidad de un clientelismo político, relacional, en los beneficiarios de las emergencias.

El núcleo central de la red visualiza lazos que refieren a los grados de confianza vincular, porque poseen un capital social inmediato, mediante el capital social de unión, de puente y 
prácticamente poco de escalera. Por este motivo, refleja la vinculación de los beneficiarios de este tipo de programas sociales con intermediaciones políticas clientelares, de tipo estratégico afectivo, y con capacidad de resolución.

El tipo de intermediador es el puntero, como ya se mencionó, pero una variante de la acción del puntero vinculada a movimientos sociales más que a partidos políticos, o sus facciones. El tipo de distribución que se realiza es clientelar-político/social, y no clientelarprogramática, porque tal figura no está definida en las reglas de operación de los programas o prestaciones.

\section{CONCLUSIONES}

Según las categorías analizadas, la personalización o individuación del vínculo, donde temas como el afecto y el compromiso por parte de los clientes puede hacer más eficiente el desarrollo del clientelismo, la legitimidad de la relación, la obligatoriedad de la retribución, el posicionamiento en las redes y el tipo de capital social asociado, indican que la presencia del clientelismo asume características diferentes según sean las condiciones de implementación, correspondiendo a la naturaleza -organización- de la tarea y al nivel de interacción entre los actores; ello significa que varía según los tipos de programas sociales en estudio, a saber:

1. Programas de entrega de bienes y recursos directos, donde la tarea es homogénea, estandarizada y la interacción con los usuarios es baja, el clientelismo se invisibiliza, por la baja necesidad de intermediación, como en el caso de la AUH. En programas con un nivel de organización de la tarea si bien homogéneo pero no riguroso, el clientelismo asume el rostro del "gestor", "como líder comunitario que tiene conocimientos de la burocracia y de los partidos políticos, que gestiona trámites y proyectos para sus seguidores" (Durston, 2005), siendo el caso de las beneficiarias del PMV donde la intermediación es clientelar-programática.

2. Programas de entrega de servicios profesionales, como son los del área clásica de la política social no asistencial, aquellos de salud y educación. Se caracterizan por una organización de la tarea homogénea, donde la interacción con los usuarios es media. En dicha tipología, al clientelismo se lo reconoce como un tipo de relación evidente, en tanto intermediación clientelar-política. El intercambio que se genera en la práctica clientelar es de tipo partidario, y la perspectiva de los destinatarios es la estratégica. Asimismo, se evidencia la presencia de intermediación clientelar programática, a cargo de una monitora que es referente social barrial (no política).

3. Programas cuyo objetivo es el desarrollo de capacidades, que se caracterizan por tener un estilo de organización de la tarea heterogéneo y un alto nivel de interacción con los usuarios. Considerando que dichos programas tienen por objetivo el empoderamiento, participación, la autogestión, requiere un tipo de beneficiario con motivación o capacidades en esa línea, por consiguiente no es de extrañar que se presente aquí un tipo de relación clientelar de reconocimiento, aceptación y superación, generando estrategias propias. Se evidencia la presencia de intermediación tanto clientelar-política, como el surgimiento de líderes que son autointermediadores (programáticos) -no clientelar-político-. 
4. Programas de emergencia, tanto habitacional como de alimentos, se caracterizan por un tipo de organización heterogénea, según la necesidad, y por baja interacción con sus usuarios. Las relaciones clientelares están presentes, ya que son el recurso humano que intermedia en la resolución de la precariedad. En este caso el tipo clientelar se asemeja a varios rostros de interdependencia, subtipos de bróker, desde el puntero, el gestor, hasta el altruista. Se evidencia la intermediación clientelar-política.

De este modo, cuando la interacción es baja o nula, los beneficiarios tienden a invisibilizar el clientelismo o a verlo como una forma efectiva para suplir sus necesidades. Sin embargo, las relaciones que se establecen entre el cliente/patrón van a depender de la retribución que se otorgue, no generando lazos identitarios ni mayores compromisos políticos entre quienes desean participar en la práctica.

Cuando la interacción es media o alta es posible observar mayores características clientelares en los beneficiarios, se visibiliza la práctica, se la denosta, se la valora, se la supera. Aparece un mayor conocimiento sobre las estrategias utilizadas en la captación de votos y recursos, y es posible encontrar redefiniciones de las prácticas en los mismos beneficiarios al ser capaces de generar iniciativas propias para la obtención de los recursos.

Finalmente, el presente estudio abre la mirada a las múltiples posibilidades de desarrollar y reconocer las prácticas clientelares, en este caso alejadas de la concepción solamente política, y más bien observadas desde la arena de la implementación de los programas sociales. El vínculo clientelar es variopinto y traspasa la mirada clásica del mismo, es un vínculo complejo, ya que refiere a "un conjunto de intercambios, tanto políticos como sociales o afectivos y, muchas veces, invisibles a los ojos de la teoría política" (Barozet, 2006). Queda pendiente para un próximo estudio indagar si la relación clientelar programática tiene un efecto en la distribución del poder, y cuáles son sus ganancias directas o cuál es el efecto de esta práctica en la implementación.

\section{BIBLIOGRAFÍA}

Álvarez Rivadulla, M. (2012): Clientelism or something else? Squatter politics in Montevideo, Latin American Politics and Society, 54 (1), pp. 37-63.

Aguirre, J. (2012): Redes clientelares. Una perspectiva teórica desde el análisis de redes sociales, Documento de trabajo, 83, Centro Interdisciplinario para el Estudio de Políticas Públicas, Buenos Aires.

Alonso, G. (2007): Acerca del clientelismo y la política social: reflexiones en torno al caso argentino, Revista del CLAD Reforma y democracia, 37, pp. 1-10.

(2011): Acerca del clientelismo y la política social: Reflexiones en torno al caso argentino. En A. Idiart (Ed.): Estado benefactor y políticas sociales, Biblos Investigaciones y Ensayos, Buenos Aires, pp.103-120.

Arriagada, I., F. Miranda y T. Pavez. (2004): Lineamientos de acción para el diseño de programas de superación de la pobreza desde el enfoque del capital social. Guía conceptual y metodológica, CEPAL-Serie Manuales, 36. 
Auyero, J. (2001): La política de los Pobres: Las prácticas clientelistas del Peronismo, Ediciones Manantial, Buenos Aires.

(2002): Clientelismo político en Argentina: doble vida y negación colectiva, Perfiles Latinoamericanos, 20, pp. 33-52.

(2004): Clientelismo político. Las caras ocultas, Capital Intelectual, Buenos Aires. (2013): Pacientes del Estado, Eudeba, Buenos Aires.

Auyero, J., L. Joseph y M. Mahler, M. (eds.) (2007): New perspectives in political ethnography, Springer, Nueva York.

Bardach, J. y R. Eccles (1991): Price, authority and trust: from ideal types to plural forms, en J. F. G.Thompson: Markets, Hierarchies and Networks, London: Sage, Londres, pp. 277-292.

Barozet, E. (2006): Relecturas de la noción de clientelismo: una forma diversificada de intermediación política y social, Ecuador Debate, 69, pp. 77-102.

Bertranou, F., O. Cetrángolo, C. Grushka y L. Casanova (2011): Encrucijadas en la seguridad social argentina: Reformas, cobertura y desafíos para el sistema de pensiones, OIT-CEPAL, Buenos Aires.

Brehm, J. y S. Gates, (1999): Working, shirking and sabotage: Bureaucratic response to a democratic public, University of Michigan Press, Ann Arbor.

Bourdieu, P. (1998): El sentido práctico, Siglo XXI, Tucumán.

Bustelo, E. (1998): El abrazo. Reflexiones entre el Estado y los Organismos No gubernamentales. Revista de Ciencias Sociales, 9.

CEPAL (2011): Panorama social de América Latina, CEPAL, Santiago.

Cravacuore, D. (2002): El líder local innovador y su concepto de articulación entre Estado y Sociedad Civil. Reflexiones a partir del análisis de programas sociales gestionados en municipios bonaerenses, Primer Congreso 17 Nacional de Políticas Sociales, Asociación Argentina de Políticas Sociales, Universidad Nacional de Quilmes.

Durston, J. (2002b): El capital social campesino en la gestión del desarrollo rural. Díadas, equipos, puentes y escaleras, CEPAL, Santiago.

(2005): Concertación social y clientelismo rural en el 'Norte Chico' de Chile (los campesinos del PRODECOP y del CDL), Debate Agrario, 40-41, pp. 349-379.

Espinoza, V. (2006): Los nuevos agentes políticos locales: Revisión estructural de la tesis de Arturo Valenzuela, ¿Cómo se articulan el nivel de representación local con el nacional en la arena local y qué papel juegan el gobierno central y las políticas públicas?, Revista Mad, 14, pp. 8-18.

Horowitz, J. (2007): Patrones y clientes: el empleo municipal en el Buenos Aires de los primeros gobiernos radicales (1926-1930), Desarrollo Económico-Revista de Ciencias Sociales, 46 (184), pp. 569-596.

Maldonado, J. (2011): Hagamos entre todos la política pública. Una reflexión sobre la visión relacional de la política pública, Polis, 7 (2), pp. 273-281.

Mardones Z, R. (2008): Chile: Transantiago recargado, Revista Ciencia Política, 28 (1), 103-119.

Martínez Nogueira, R. (2004): Desafíos estratégicos en la implementación de políticas sociales: Provisión, participación y coordinación, Grupo CEO-Universidad de Buenos Aires, Buenos Aires. 
(2007): Desafíos estratégicos en la implementación de programas sociales, en J.C. Cortázar: Entre el diseño y la evaluación. El papel crucial de la implementación de los programas sociales, BID, Washington D.C.

Matus, A. (2007): Prácticas clientelares y representaciones sociales en un barrio de la ciudad de Neuquén, Argentina, Argumentos, 20 (44), pp. 105-121.

Merklen, D. (2005): Pobres ciudadanos. Las clases populares en la era democrática (Argentina, 19832003), Gorla, Buenos Aires.

(2006): Los pobres están condenados a la participación, Página 12, 23 de enero.

Orlansky, D. y A. Makón (2007): Beneficiarios de planes sociales: su inserción en el sector público, Octavo Congreso Nacional de Estudios del Trabajo.

Peralta, M.I. (2006): Las estrategias del clientelismo 'social', Espacio, Buenos Aires.

Peroni, A. (2010): Gestión de programas sociales: material docente, Pontificia Universidad Católica de Chile, Instituto de Ciencia Política, Magíster en Ciencia Política.

PNUD (2004): La democracia en América Latina. Hacia una democracia de ciudadanas y ciudadanos, PNUD, Buenos Aires.

Rehren, A. (2000): Clientelismo político, corrupción y reforma del Estado en Chile, Centro de Estudios Públicos, Santiago.

Roniger, L. y S. Eisenstadt (1984): Patrons, clients and friends: Impersonal relations and the structure of trust in society, Cambridge University Press, Cambridge.

Stiglitz, J. (2000): La economía del sector público, Antoni Bosch, Barcelona.

Soprano, G. (2008): Doña Silvia Análisis de Redes Políticas en el Peronismo de la Provincia de Misiones durante una Campaña Electoral, Andes, 19, 119-155.

Szwarcberg, M.L. (2010): El clientelismo en democracia: lecciones del caso argentino, Nueva Sociedad, 225.

Tilly, C. (1991): Grandes estructuras, procesos amplios, comparaciones enormes, Alianza Editorial, Madrid.

Torres, P. (2002): Votos, chapas y fideos: Clientelismo político y ayuda social, De la Campana, La Plata.

Tosoni, M. (2010): Niklas Luhmann y Pierre Bourdieu: claves teóricas para la interpretación del clientelismo en Argentina, Estudios sociológicos, 28 (83), pp. 359-381.

UNICEF y CEPAL (2006): Efectos de la crisis en Argentina: La políticas del Estado y sus consecuencias para la infancia, UNICEF/CEPAL, Buenos Aires.

Villasante, T. (2006): Redes y conjuntos de acción: para aplicaciones estratégicas en los tiempos de la complejidad social, REDES-Revista Hispana para el de Análisis de Redes Sociales, 11 (2).

Valenzuela A. (1977): Political broker in Chile: Local government in a centralized polity, Duke University Press, Durham.

Vommaro, G. y J. Quiros, (2011): Usted vino por su propia decisión: repensar el clientelismo en clave etnográfica, disponible en http://www.scielo.org.mx/ (consultado el 26 de agosto de 2012).

Zaremberg, G. (2004): Alpargatas y libros: estilos de gestión, género y política social en Chile y Argentina, CEPAL, Santiago. 
IMPLEMENTACIÓN DE LA POLÍTICA SOCIAL: ESPACIO DE INTERMEDIACIÓN... 115

Zambrano, A., G. Bustamante y M. García (2009): Trayectorias organizacionales y empoderamiento comunitario: Un análisis de interfaz en dos localidades de la Región de la Araucanía, Psykhe, 18 (2), pp. 65-78.

Recibido: 4-1-2016

Aceptado: 7-3-2016 


\section{ANEXO}

TABLA 3

Tipos de actores presentes en la implementación y simbología utilizada en las gráficas de redes sociales

\begin{tabular}{|c|c|c|}
\hline TIPO DE ACTOR & DESCRIPCIÓN & SÍMBOLO \\
\hline $\begin{array}{l}\text { Intermediaria/o } \\
\text { entrevistada }\end{array}$ & $\begin{array}{l}\text { Refiere a quien ejerce un rol de liderazgo en la comunidad, y } \\
\text { se ubica entre el Estado y los beneficiarios. En Chile, suelen ser } \\
\text { dirigentes de organizaciones sociales o territoriales. En Argentina, } \\
\text { son "referentes barriales" articuladores de movimientos u } \\
\text { organizaciones sociales o políticos, o implementadores de } \\
\text { programas locales (manzaneras/monitoras de salud/ encargadas } \\
\text { de comedores/coordinador de cooperativas). }\end{array}$ & \\
\hline Intermediaria/o & $\begin{array}{l}\text { Igual descriptor anterior, solo mencionado en las encuestas } \\
\text { de redes. }\end{array}$ & \\
\hline $\begin{array}{l}\text { Beneficiario/a } \\
\text { entrevistada }\end{array}$ & $\begin{array}{l}\text { Receptor de los beneficios del programa sobre el cual fue } \\
\text { entrevistada/ } 0 \text {. }\end{array}$ & \\
\hline Beneficiario/a & $\begin{array}{l}\text { Receptor de los beneficios de la política social, mencionado/a } \\
\text { en las encuestas de redes, por los entrevistados. }\end{array}$ & \\
\hline Funcionario/a & Ejecutor/a de los programas sociales. & \\
\hline Contacto político & $\begin{array}{l}\text { Agente estatal de amplio espectro, no vinculado directamente } \\
\text { a la ejecución de la tipología, por ejemplo, alcalde, consejal/ } \\
\text { concejal, jefe de gabinete, funcionario de otra repartición, } \\
\text { miembro de un partido político. O referente extracomunidad, } \\
\text { por ejemplo líder religioso. }\end{array}$ & \\
\hline Otro rol & $\begin{array}{l}\text { No se conoce el rol que desempeña, se presupone que son } \\
\text { beneficiarios o articuladores políticos barriales. }\end{array}$ & \\
\hline
\end{tabular}

Fuente: Elaboración propia. 